\title{
PROBABILITY DENSITY FUNCTIONS OF VOLTAGE SAGS MEASURED INDICES
}

\author{
Zvonimir KLAIĆ — Damir ŠLJIVAC — Zoran BAUS *
}

\begin{abstract}
Voltage sags can cause interruptions of industrial processes, which could result as a malfunction of equipment and considerable economic losses. Thus, it is very useful to see certain rules of voltage sags occurrence due to duration and depth.

This paper presents statistical analyses of voltage sags in several domestic and industrial transformer stations. Voltage sag probability functions are calculated from actual measurement data, by means of a hill climbing algorithm. Lognormal and Weibull frequency distribution functions are used to describe distribution of measured voltage dips.

K e y w or d s: power quality, voltage sag, probability functions, chi squared criterion, hill climbing algorithm
\end{abstract}

\section{INTRODUCTION}

Electrical appliances become more complex due to complicated functions and mutual interactions. There are many advantages of automated manufactory systems and variable speed drives in industry, as well as information systems and fluorescent lights at the public and domestic consumers. Therefore, development of these systems and equipment is very fast and its usage is growing. Most of nowadays electrical equipment is more sensitive to deviations from sinusoidal supply voltage. At the same time, the same or other equipment cause modifications to the characteristics of the supply voltage, $[1,2]$.

Costs of power quality disturbances (interruptions, voltage sags, harmonics, surges etc) are very significant and have the highest impact on industry. In order to minimize those costs, it is necessary to analyze the electrical system and then try to determine possible future problems. Only after that, it is possible to improve the system in a right way.

\section{VOLTAGE SAGS}

Voltage sags are the most frequent cause of power quality problems. They introduce considerable economic losses and have the high impact on industry and other consumers. The most sensitive applications are continuous production lines, (paper mill, cement production etc) lighting and safety systems and computer equipment. Although voltage sag could not cause such damage in industry as an interruption could, the total damage due to voltage sags is larger, because in a long period (a year or longer) there are more sags then interruptions, [3, 4]. Thus, from an economic point of view the dip frequency, $i e$ the annual number of dips, is very important. When assessing the total annual dip related cost, one has to find out how many dips are expected. Some rough estimation can be acquired from measurement over a shorter period. Another approach is to use stochastic mathematical methods for assessing more precise figures.

\subsection{RMS Variation Indices}

SARFI (System Average RMS Variation Frequency In$d e x)$ is a power quality index that provides a count or rate of voltage sags, swells, and/or interruptions for a system. It should be seen as the voltage sag equivalent of SAIFI as defined for interruptions [5]. SARFI can be defined as a single monitoring location, a single customer service, a feeder, a substation, groups of substations, or for an entire power system.

$\mathrm{SARFI}_{X}$ is a power quality index that represents the average number of specified RMS variation measurement events that occurred over the assessment period, where the specified disturbances are those with a magnitude less than $x$ for sags or a magnitude greater than $x$ for swells

$$
\mathrm{SARFI}_{X}=\frac{N_{E}}{D} \cdot 30 \text { days }
$$

where $N_{E}$ is the number of events and $D$ is the number of days measured at a single site.

System Instantaneous Average RMS (Variation) Frequency Index $\left(\mathrm{SIARFI}_{X}\right)$ represents the average number of specified instantaneous RMS variation measurement events that occurred over the assessment period. The specified disturbances are those with a magnitude less than $x$ for sags or a magnitude greater than $\mathrm{x}$ for swells and duration in the range of $10-500 \mathrm{~ms}$ [6].

$\mathrm{SMARFI}_{X}$ is defined for variations having durations in the range of $500 \mathrm{~ms}$ to 3 seconds for sags and swells and in the range of $10 \mathrm{~ms}$ to 3 seconds for interruptions.

* The Faculty of Electrical Engineering, J. J. Strossmayer University of Osijek, Kneza Trpimira 2b, 31000 Osijek, Croatia, zoran.baus@tvz.hr 


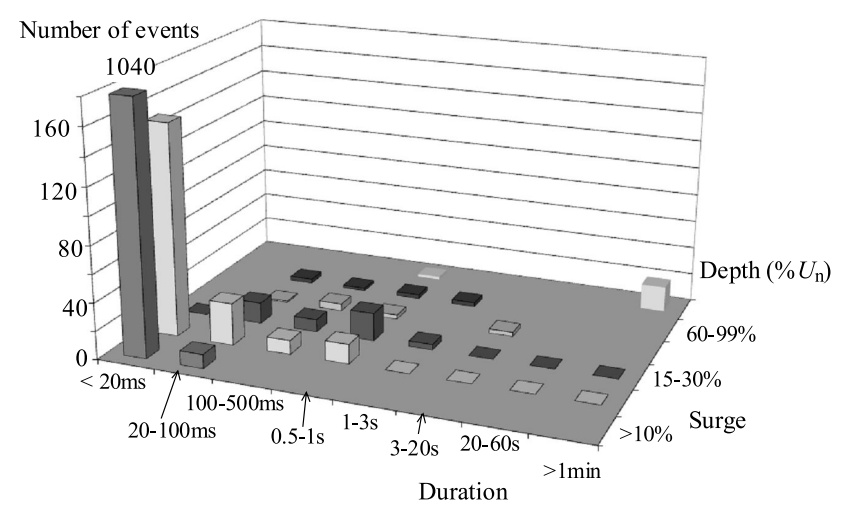

Fig. 1. Voltage events for domestic transformer stations

Table 1. Voltage events for domestic transformer stations

\begin{tabular}{l|cccccccc}
\hline Phase & $<20$ & 20 & 0.1 & 0.5 & 1 & 3 & 20 & $>60$ \\
L1,L2,L3 & & -100 & -0.5 & -1 & -3 & -20 & -60 & \\
& $(\mathrm{~ms})$ & $(\mathrm{ms})$ & $(\mathrm{s})$ & $(\mathrm{s})$ & $(\mathrm{s})$ & $(\mathrm{s})$ & $(\mathrm{s})$ & $(\mathrm{s})$ \\
\hline Surge $>10 \%$ & 1040 & & 10 & & & & & \\
Sag $>10 \%$ & & & & & & & & \\
$10-15 \%$ & 152 & 30 & 10 & 14 & & & & \\
$15-30 \%$ & & 15 & 9 & 20 & 4 & & & \\
$30-60 \%$ & & 1 & 5 & 3 & & 3 & & \\
$60-99 \%$ & & 3 & 2 & 3 & 3 & & & \\
Interruption & & & & 2 & & & & 18 \\
\hline
\end{tabular}

System Temporary Average RMS (Variation) Frequency Index $\left(\mathrm{STARFI}_{X}\right)$ is defined for temporary variations which have durations in the range of 3-60 seconds.

\section{PROBABILITY DISTRIBUTION FUNCTIONS}

Probability distribution functions are mathematical equations allowing a large amount of information, characteristics and behavior to be described by a small number of parameters [7]. A probability distribution function has an associated density function $f(x)$, that represents the likelihood that a random variable $x$ will be a particular value. In this paper, lognormal and Weibull probability functions are used for describing actual voltage dip distributions.

When probability distribution curves are used to represent empirical data, the information associated with thousands of data points can be modeled with one or two parameters.

\subsection{Chi Squared Criterion}

The chi squared criterion is used to identify distribution function parameters, and it is also used to compare the fit of lognormal and Weibull functions to a voltage dip distribution. Chi squared criterion $\left(\chi^{2}\right)$ indicates how well a model matches the data that it is supposed to represent [7]. When a number $\chi^{2}$ is smaller, it means that modeled curve better matches actual data curve. Chi squared criterion is based on density functions and data bin densities

$$
\begin{aligned}
& \chi^{2}=\sum_{\text {bins }} \frac{(\text { Observed Freq. in Bin }- \text { Expected Freq. in Bin })^{2}}{\text { Expected Freq. in Bin }} \\
& \text { Observed Freq. in Bin }=\frac{\text { Number of Samples in Bin }}{\text { Total Number of Samples }},(3) \\
& \text { Expected Freq. in Bin }=\int_{a}^{b} f(x) \mathrm{d} x=F(b)-F(a) \\
& \qquad \operatorname{Bin}=a \leq x \leq b .
\end{aligned}
$$

A hill climbing algorithm is used for minimizing the chi squared error of a curve fit, [7]:

1. Initialize parameters to achieve a reasonable fit.

2 . Set $\Delta$ equal to the precision desired for each parameter.

3. Compute $\chi^{2}$.

4. Start with the first parameter, $p$.

5. Compute $\chi_{\text {test }}^{2}$, based on $p_{\text {test }}=p+\Delta$.

6. If $\chi_{\text {test }}^{2}<\chi^{2}$ then set $p=p_{\text {test }}$, set $\chi^{2}=\chi_{\text {test }}^{2}$, and go to step 9 .

7. Compute $\chi_{\text {test }}^{2}$, based on $p_{\text {test }}=p-\Delta$.

8. If $\chi_{\text {test }}^{2}<\chi^{2}$ then set $p=p_{\text {test }}$, set $\chi^{2}=\chi_{\text {test }}^{2}$.

9. Repeat steps 5-9 for all parameters.

10. Has $\chi^{2}$ changed its value since step 4 ? If so go to step 4.

11. End.

This algorithm guarantees that the parameters are locally optimal, so initial parameters, which generally represent the shape of the data set, were obtained by trial and error.

\section{FITTING CURVES TO MEASURED DATA}

Measurements were performed on several (26) MV/LV transformer stations with domestic and industrial consumers. Most of domestic transformer stations were located in urban area, and industrial consumers were paper mill, cement factory, dairy and sugar industry, brewery, wine- cellar, beverage industry, wood and rubber industry. Measurement period used for each consumer was one week, according to the European standard EN 50160.

\subsection{Domestic Consumers}

Table 1 and Figure 1 represent summed voltage events for domestic transformer stations measurements. Total number of measured voltage sags is 277 and most voltage sags are found in two depth categories: $10-15 \% U_{n}$ and $15-30 \% U_{n}$.

Figures 2 and 3 (retrieved from Table 1) represent $10-15 \% U_{n}$ and $15-30 \% U_{n}$ voltage sag distributions, and 


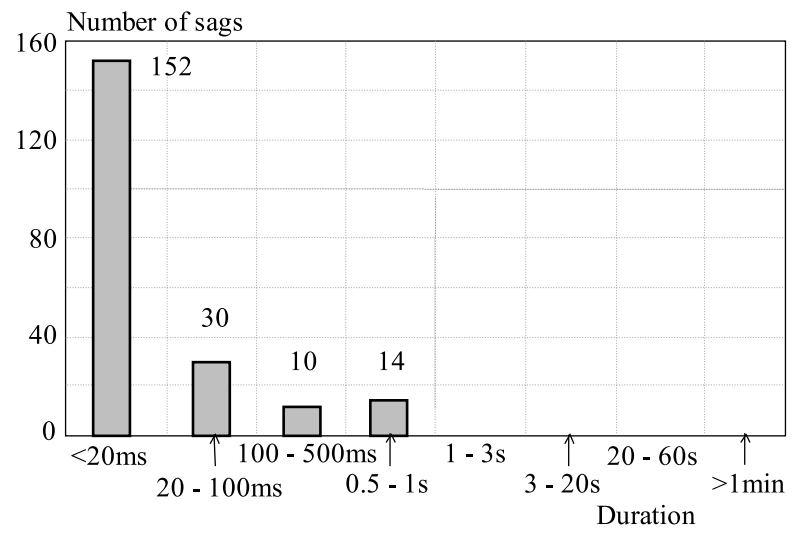

Fig. 2. $10-15 \% U_{n}$ voltage sag distribution - domestic transformer stations

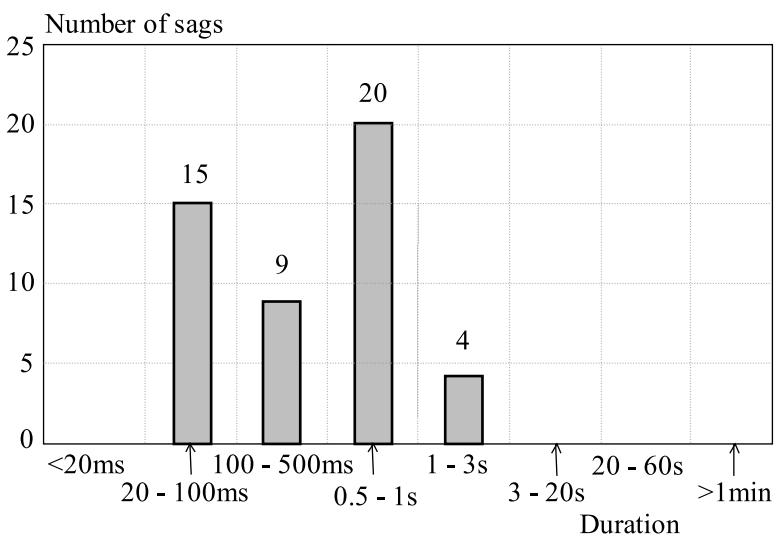

Fig. 3. $15-30 \% U_{n}$ voltage sag distribution - domestic transformer stations

Table 2. Calculation of lognormal distribution for $10-15 \% U_{n}$ sags

\begin{tabular}{|c|c|c|c|c|c|c|c|c|c|}
\hline Duration & $<20 \mathrm{~s}$ & $20-100 \mathrm{~s}$ & $0.1-0.5 \mathrm{~s}$ & $0.5-1 \mathrm{~s}$ & $1-3 \mathrm{~s}$ & $3-20 \mathrm{~s}$ & $20-60 \mathrm{~s}$ & $>60 \mathrm{~s}$ & $\chi^{2}$ \\
\hline Number $f_{i}$ & 152 & 30 & 10 & 14 & 0 & 0 & 0 & 0 & \\
\hline $\begin{array}{c}\operatorname{Logn} 1 f_{t i} \\
\left(f_{i}-f_{t i}\right) 2 / f_{t i} \\
\end{array}$ & $\begin{array}{l}\text { Lognorr } \\
152.256 \\
0.00043 \\
\end{array}$ & $\begin{array}{r}\text { mal } 1 \sigma 1= \\
32.58097 \\
0.204457\end{array}$ & $\begin{array}{r}=19 \mu 1= \\
6.921776 \\
1.368935\end{array}$ & $\begin{array}{l}12 \\
3.544178 \\
30.84614 \\
\end{array}$ & $\begin{array}{l}1.223411 \\
1.223411 \\
\end{array}$ & $\begin{array}{l}0.19339 \\
0.19339 \\
\end{array}$ & $\begin{array}{l}0.066147 \\
0.066147 \\
\end{array}$ & $\begin{array}{l}0.033557 \\
0.033557 \\
\end{array}$ & 33.93647 \\
\hline $\begin{array}{c}\operatorname{Logn} 2 f_{t i} \\
\left(f_{i}-f_{t i}\right) 2 / f_{t i}\end{array}$ & $\begin{array}{l}\text { Lognorr } \\
151.680 \\
0.00067 \\
\end{array}$ & $\begin{array}{r}\text { nal } 2 \sigma 2= \\
33.47564 \\
0.360861\end{array}$ & $\begin{array}{c}=16 \mu 2= \\
7.313201 \\
0.987104\end{array}$ & $\begin{array}{l}12.5 \\
3.786442 \\
27.55008 \\
\end{array}$ & $\begin{array}{l}1.328765 \\
1.328765 \\
\end{array}$ & $\begin{array}{l}0.215409 \\
0.215409 \\
\end{array}$ & $\begin{array}{l}0.074621 \\
0.074621 \\
\end{array}$ & $\begin{array}{l}0.038135 \\
0.038135 \\
\end{array}$ & 30.55565 \\
\hline $\begin{array}{c}\operatorname{Logn} 3 f_{t i} \\
\left(f_{i}-f_{t i}\right) 2 / f_{t}\end{array}$ & $\begin{array}{l}\text { Lognorr } \\
151.552 \\
0.00132\end{array}$ & $\begin{array}{c}\text { nal } 3 \sigma 3= \\
33.53143 \\
0.37192\end{array}$ & $\begin{array}{r}=15.8 \mu 3 \\
7.341888 \\
0.962363\end{array}$ & $\begin{array}{l}=12.5 \\
3.804675 \\
27.32024\end{array}$ & $\begin{array}{l}1.336914 \\
1.336914 \\
\end{array}$ & $\begin{array}{l}0.217159 \\
0.217159 \\
\end{array}$ & $\begin{array}{l}0.075301 \\
0.075301\end{array}$ & $\begin{array}{l}0.038504 \\
0.038504\end{array}$ & 30.32373 \\
\hline
\end{tabular}

from figures, it is obvious that there were much more voltage sags in $10-15 \% U_{n}$ depth category (206), than in $15-30 \% U_{n}$ (48).

The next step was to compare above mentioned distributions to lognormal and Weibull probability distributions, by the chi squared criterion. A hill climbing algorithm, which is used for minimizing the chi squared error of a curve fit, was performed by Visual Basic program.

For each voltage sag distribution, initial parameters that already represent the general set of a data set were obtained by trial and error. Only after that, algorithm was initialized by these initial parameters, and optimal parameters were obtained in several steps, as required.

Table 2 represents calculation of parameters for lognormal distribution for $10-15 \% U_{n}$ sags, domestic consumers. Three steps were needed to calculate optimal parameters: $\sigma=15.8$ and $\mu=12.5$ with $\chi^{2}=30.32373$. Thus, lognormal probability distribution which best describes $10-15 \% U_{n}$ voltage dip distribution is

$$
f(x)=\frac{1}{15.8 \sqrt{2 \pi} x} \exp \left[-\frac{(\ln x-12.5)^{2}}{2 \cdot 15.8^{2}} .\right.
$$

Optimal parameters for Weibull function are $\alpha=1$, $\beta=0.04$ and $\chi^{2}=43.51809$. So, the best Weibull probability function which describe $10-15 \% U_{n}$ voltage dip distribution is

$$
f(x)=0.04 x^{0.04-1} \exp \left(-x^{0.04}\right) .
$$

Although both probability distributions (lognormal and Weibull) fit $10-15 \% U_{n}$ voltage dip distribution pretty well and their curves have similar shapes (figure 4), lognormal probability distribution has lower chi square error $\chi^{2}=30.32373$. So, lognormal probability distribution with parameters $\sigma=15.8$ and $\mu=12.5$ is most suitable for describing $10-15 \% U_{n}$ voltage dip distribution.

Similar procedure was applied to calculate optimal parameters for $15-30 \% U_{n}$ sags. But, it is worth noting that there are significantly less data in this voltage depth category (Fig. 3).

Optimal parameters for lognormal distribution $\sigma=$ 1.398 and $\mu=0.773$ with $\chi^{2}=12.08993$ were obtained in four steps, Fig. 5. Although curves Lognormal 3 and Lognormal 4 have almost identical shapes, for Lognormal $3 \chi=12.15388$, which is higher value of Lognormal 4 . Thus, lognormal probability distribution which best describes $15-30 \% U_{n}$ voltage dip distribution is

$$
f(x)=\frac{1}{1.398 \sqrt{2 \pi} x} \exp \left[-\frac{\ln x-0.773)^{2}}{2 \cdot 1.398^{2}}\right] .
$$




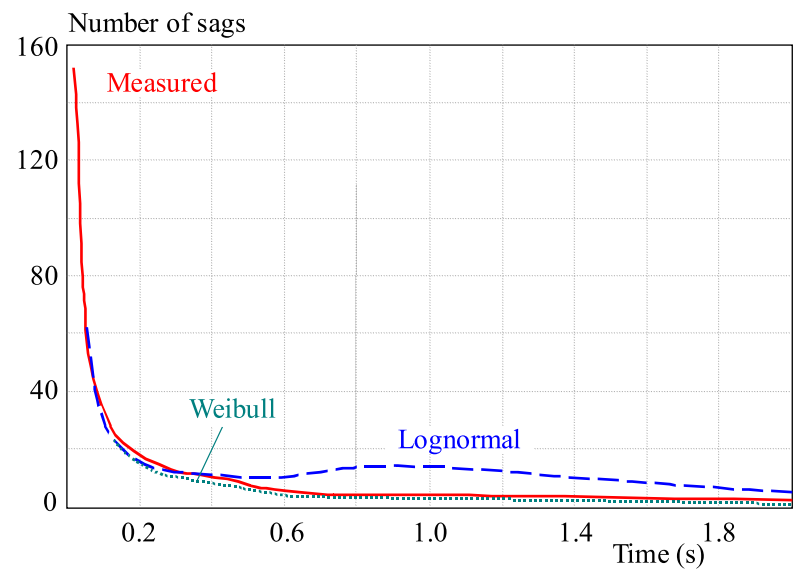

Fig. 4. Calculated probability distributions for $15-30 \% U_{n}$ voltage sags - domestic transformer stations

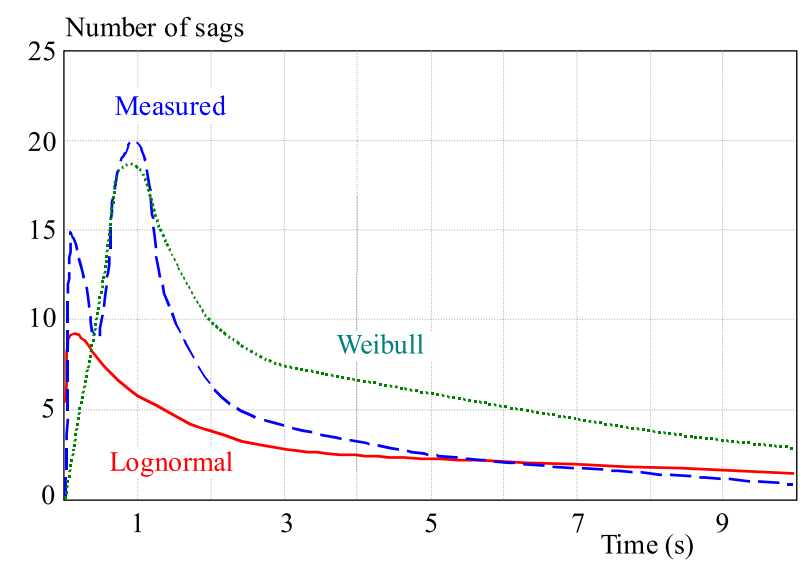

Fig. 6. Calculated probability distributions for $15-30 \% U_{n}$ voltage sags - domestic transformer stations

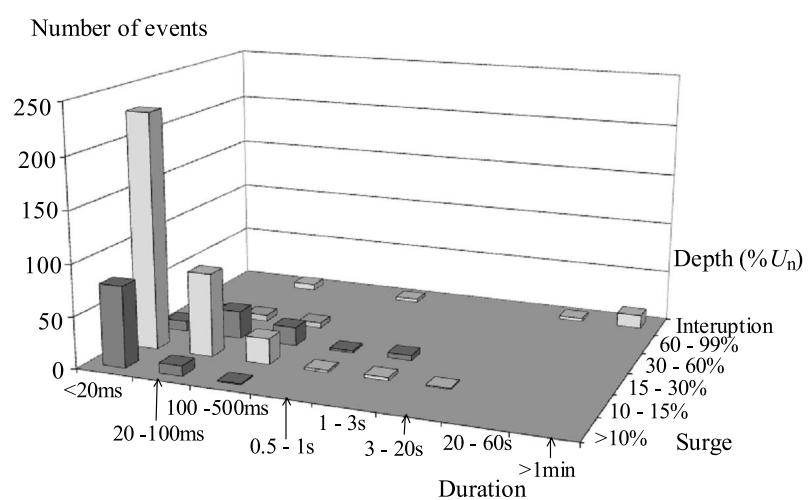

Fig. 7. Voltage events for industrial transformer stations

Optimal parameters for Weibull function are $\alpha=$ $2.099, \beta=1.439$ and $\chi^{2}=13.86839$ and the best Weibull probability function which describes $15-30 \% U_{n}$ voltage dip distribution is

$$
f(x)=\frac{1.439 x^{1.439-1}}{2.099^{1.439}} \exp \left[-\left(\frac{x}{2.099}\right)^{1.439}\right]
$$

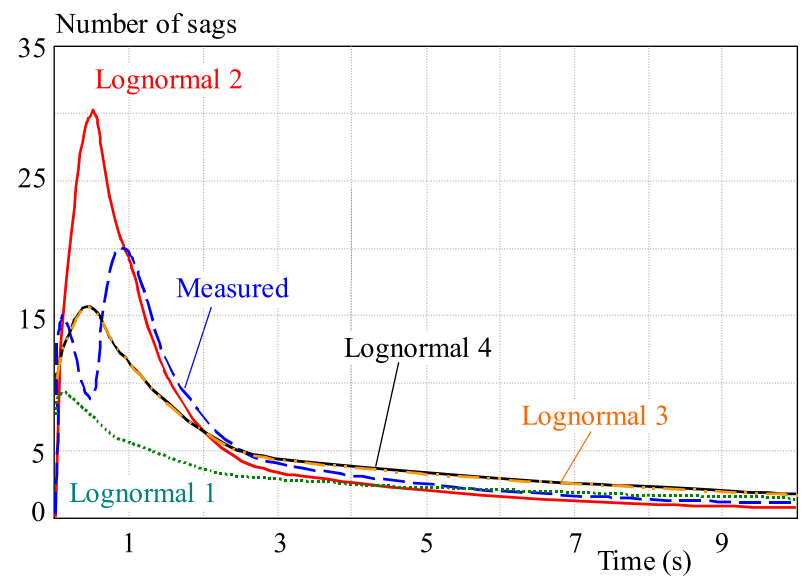

Fig. 5. Lognormal probability distributions for $15-30 \% U_{n}$ voltage sags domestic transformer stations

Again, lognormal probability distribution has lower chi square error $\left(\chi^{2}=12.08993\right)$. So, lognormal probability distribution with parameters $\sigma=1.398$ and $\mu=0.773$ is most suitable for describing $15-30 \% U_{n}$ voltage dip distribution.

In this case, both probability distributions (Fig. 6) do not fit $15-30 \% U_{n}$ voltage dip distribution as well as in the previous case. Possible reason for this is the fact that there were less voltage dips in this depth category, so there are also less data. Nevertheless, both probability curves in this case have significantly different shape (first ascending than descending) than in the previous case (only descending shape).

\subsection{Industrial Consumers}

Measured voltage events for industrial consumers are represented by Table 3 and Fig. 7. Total number of measured voltage sags is 419. As in case of domestic consumers, most sags are found in $10-15 \% U_{n}$ and $15-30 \% U_{n}$ depth categories. Figures 8 and 9 represent $10-15 \% U_{n}$ and $15-30 \% U_{n}$ voltage dip distributions, and as in case of domestic consumers, there were much more voltage sags in $10-15 \% U_{n}$ depth category (342), than in $15-30 \% U_{n}(62)$.

Calculation of parameters for lognormal distribution for $15-30 \% U_{n}$ voltage sags were carried out in several steps. Optimal parameters are $\sigma 3=5.325, \mu 3=5.937$ and error $\chi^{2}=12.19157$ which give lognormal probability distribution

$$
f(x)=\frac{1}{5.325 \sqrt{2 \pi} x} \exp \left[-\frac{(\ln x-5.937)^{2}}{2 \cdot 5.325^{2}}\right] .
$$

Derived optimal parameters for Weibull function are $\alpha=258.126, \beta=0.335$ with error $\xi^{2}=15.12644$. So, the best Weibull probability function which describes 10 $15 \%$ Un voltage dip distribution is

$$
f(x)=\frac{0.335 x^{0.335-1}}{258.126^{0.335}} \exp \left[-\left(\frac{x}{258.126}\right)^{0.335}\right]
$$




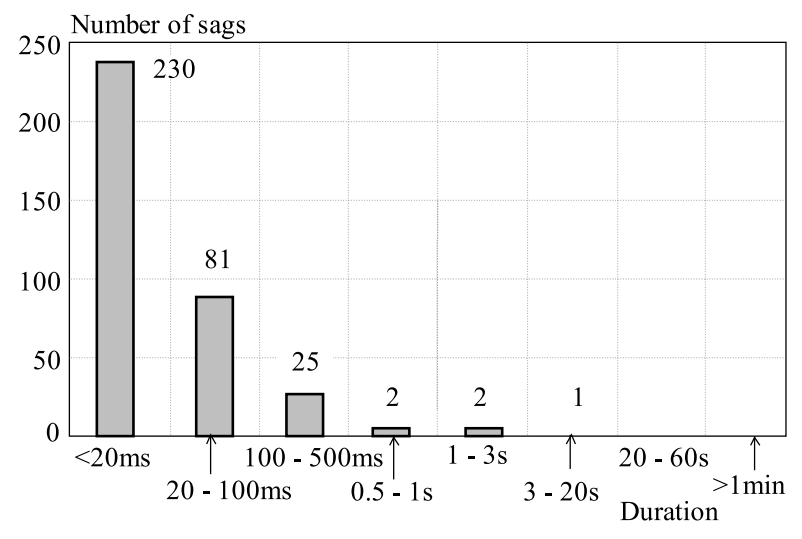

Fig. 8. $10-15 \% U_{n}$ voltage sag distribution — industrial transformer stations

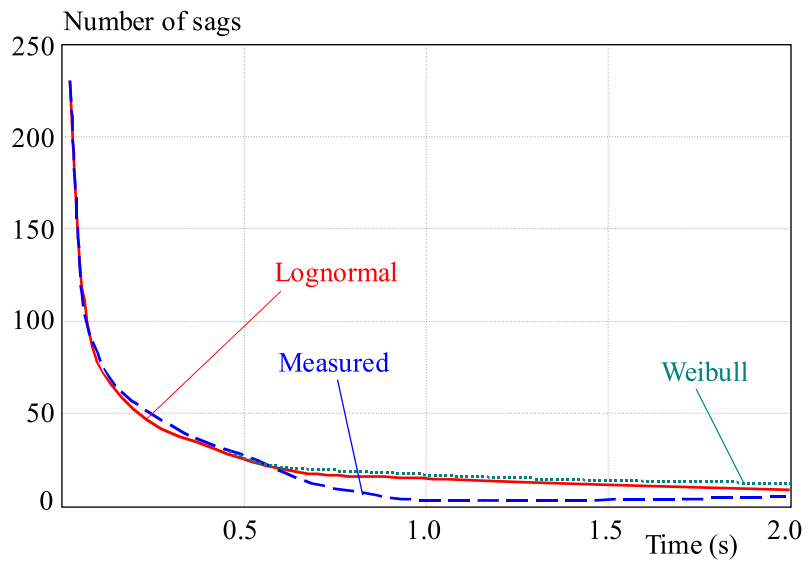

Fig. 10. Calculated probability distributions for $10-15 \% U_{n}$ voltage sags - industrial transformer stations

Table 3. Voltage events for industrial transformer stations

\begin{tabular}{l|cccccccc}
\hline Phase & $<20$ & 20 & 0.1 & 0.5 & 1 & 3 & 20 & $>60$ \\
L1,L2,L3 & & -100 & -0.5 & -1 & -3 & -20 & -60 & \\
& $(\mathrm{~ms})$ & $(\mathrm{ms})$ & $(\mathrm{s})$ & $(\mathrm{s})$ & $(\mathrm{s})$ & $(\mathrm{s})$ & $(\mathrm{s})$ & $(\mathrm{s})$ \\
\hline $\begin{array}{l}\text { Surge }>10 \% \\
\text { Sag }>10 \%\end{array}$ & 79 & & 10 & 1 & & & & \\
$10-15 \%$ & 230 & 81 & 25 & 2 & 3 & 1 & & \\
$15-30 \%$ & 10 & 27 & 18 & 2 & 5 & & & \\
$30-60 \%$ & & 4 & 6 & 5 & & & & \\
$60-99 \%$ & & & & & & & 3 & 13 \\
Interruption & & 6 & & 3 & & & &
\end{tabular}

Figure 10 represents lognormal and Weibull probability functions whose parameters fit 10-15\% voltage dip distribution for industrial transformer stations. Curve shapes in this figure are very similar to those in Fig. 4 which represents probability distributions for domestic consumers. Again, both probability distributions fit $10-15 \% U_{n}$ voltage dip distribution pretty well, but lognormal probability distribution has lower chi square error $\left(\chi^{2}=12.19157\right)$. So, lognormal probability distribution with parameters $\sigma=15.8$ and $\mu=12.5$ is most suit-

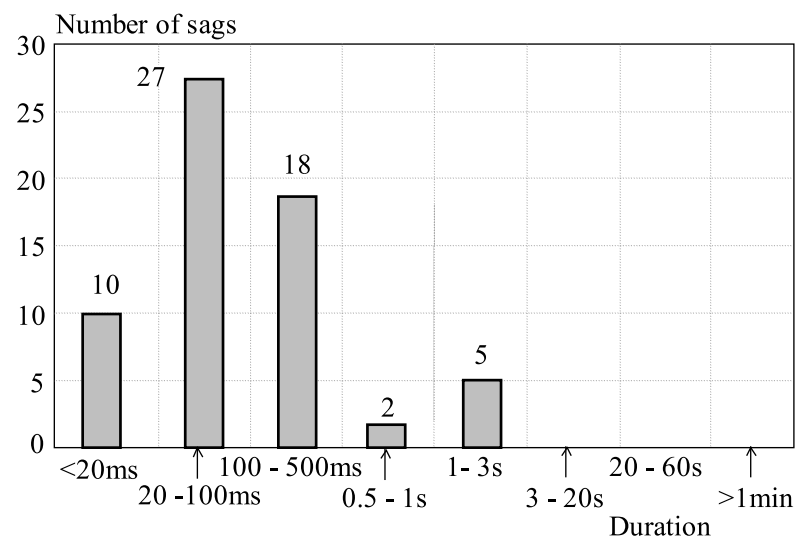

Fig. 9. $15-30 \% U_{n}$ voltage sag distribution — industrial transformer stations

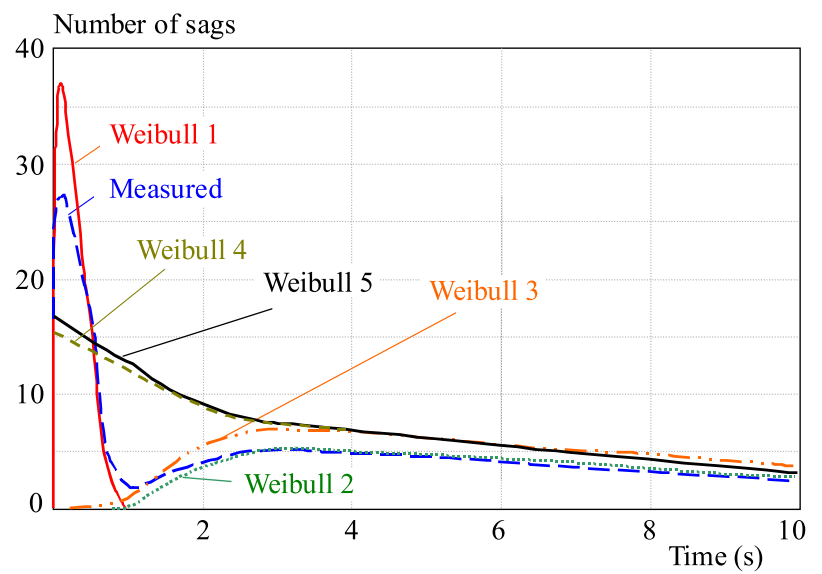

Fig. 11. Weibull probability distributions for $15-30 \% U_{n}$ voltage sags - industrial transformer stations

able for describing $10-15 \% U_{n}$ voltage sag distribution for industrial transformer stations.

Next equations are lognormal and Weibull probability distributions with optimal parameters for $15-30 \% U_{n}$ voltage dip distribution for industrial transformer stations (Fig. 9).

Lognormal optimal parameters $\sigma_{3}=1.775$ and $\mu_{3}=$ 1.065 .

Error $\chi^{2}=10.13152$.

Lognormal probability distribution

$$
f(x)=\frac{1}{1.775 \sqrt{2 \pi} x} \exp \left[-\frac{(\ln x-1.065)^{2}}{2 \cdot 1.775^{2}}\right] .
$$

Weibull optimal parameters $\alpha_{5}=3.7$ and $\beta_{5}=1$.

Error $\chi^{2}=20.42612$.

Weibull probability distribution

$$
f(x)=\frac{1}{3.7} \exp \left[-\frac{x}{3.7}\right]
$$

Figure 11 shows five trials in deriving Weibull probability distributions for $15-30 \% U_{n}$ sags. Although function Weibull 5 has minimum $\chi^{2}$ error, its shape does not fit measured voltage dip distribution very well, especially 


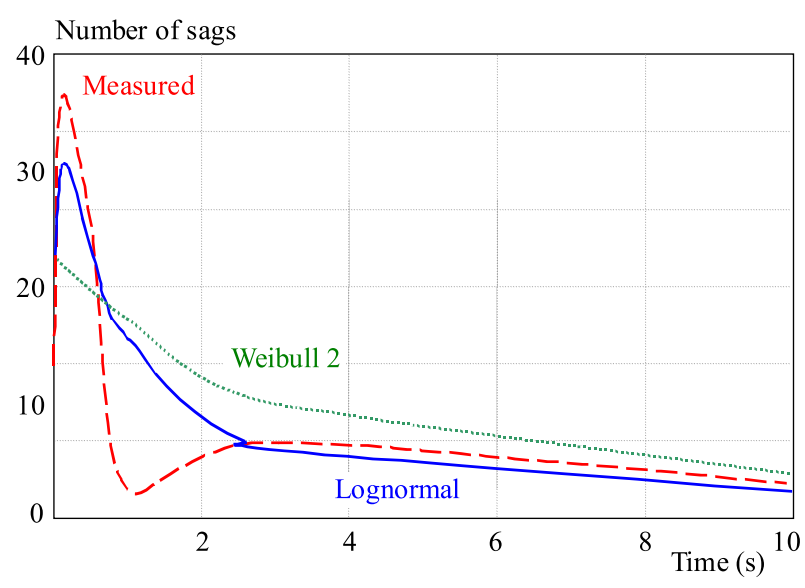

Fig. 12. Calculated probability distributions for $15-30 \% U_{n}$ voltage sags - industrial transformer stations

Table 4. RMS variation indices for the group of domestic substations

\begin{tabular}{ccccc}
\hline$x$ & $\mathrm{SARFI}_{X}$ & $\mathrm{SIARFI}_{X}$ & $\mathrm{SMARF}_{X}$ & $\mathrm{STARFI}_{X}$ \\
\hline 110 & 4500.00 & 4500.00 & 0.00 & 0.00 \\
90 & 1195.71 & 972.86 & 210.00 & 12.86 \\
85 & 312.86 & 150.00 & 150.00 & 12.86 \\
70 & 107.14 & 47.14 & 47.14 & 12.86 \\
40 & 55.71 & 21.43 & 34.29 & 0.00 \\
1 & 8.57 & 0.00 & 8.57 & 0.00 \\
\hline
\end{tabular}

Table 5. RMS variation indices for the group of industrial substations

\begin{tabular}{ccccc}
\hline$x$ & $\mathrm{SARFI}_{X}$ & $\mathrm{SIARFI}_{X}$ & $\mathrm{SMARF}_{X}$ & $\mathrm{STARFI}_{X}$ \\
\hline 110 & 385.71 & 385.71 & 0.00 & 0.00 \\
90 & 1847.14 & 1765.71 & 64.29 & 17.14 \\
85 & 381.43 & 325.71 & 42.86 & 12.86 \\
70 & 115.71 & 90.00 & 12.86 & 12.86 \\
40 & 51.43 & 25.71 & 12.86 & 12.86 \\
1 & 51.43 & 25.71 & 12.86 & 12.86 \\
\hline
\end{tabular}

in a time range of $20 \mathrm{~ms}-4 \mathrm{~s}$. On the other hand, curves Weibull 1 and Weibull 2 fit measured values pretty well, but only partially. Weibull 1 fits a part from $20 \mathrm{~ms}$ to $1 \mathrm{~s}$, and Weibull 2 farther than $1 \mathrm{~s}$. This fact gives the idea that distribution of such shape could be described more accurate by two Weibull functions.

In this case, lognormal probability distribution not only has lower chi square error $\left(\chi^{2}=10.13152\right)$, but also its shape fits measured dip distribution much better than Weibull function (Fig. 12). The shape of lognormal distribution function first ascends and then descends, as well as distribution of measured sags, while the shape of Weibull function only descends.

\section{CALCULATION OF RMS VARIATION SITE INDICES}

$\mathrm{SARFI}_{X}$ indices are very suitable due to their possibility of comparing different sites in terms of the RMS volt- age variations. Here, two groups of substations are compared by $\mathrm{SARFI}_{X}$ indices: voltage events for domestic and for industrial transformer stations. Voltage sag data from Tables 1 and 3 are used for calculating RMS variation indices. Duration of all measurements was 7 days and values in Tables 4 and 5 are recalculated to present values of voltage events per 30 days.

The calculated values are commonly expected. The System Average RMS-variation Frequency Index for industrial transformer stations is larger $\left(\mathrm{SARFI}_{90}=1847.14\right)$ than for the group of domestic transformer stations $\left(S \mathrm{ARFI}_{90}=1195.71\right)$. It is reasonable to assume that larger number of sags at industrial transformer stations occurred due to the industrial loads and equipment.

In both cases, the number of sags decrease rapidly with the voltage threshold decrease. At the domestic group, there are only 312.86 sags below $85 \%$ and only 107.14 below $70 \%$ nominal voltage, of the total 1195.71 sags per month. The number of sags at the industrial group of substations decrease even faster. The total number of sags per month is 1847.14 , there are only 381.43 sags below $85 \%$ and only 115.71 below $70 \%$ nominal voltage.

Regarding duration of events, the majority of the sags are instantaneous, particularly within the group of industrial transformer stations. Of overall 1847.14 sags, only 64.29 are momentary and 17.14 are temporary sags.

However, although RMS variation indices confirm results obtained by the probability distribution functions, RMS indices provide easier comparison of voltage sags for two above mentioned groups of substations.

\section{CONCLUSION}

Measurements of voltage events for a number of domestic and industrial transformer stations were performed, which enabled the detailed statistical analysis and derivation of probability density functions.

A measurement period used for every single consumer was one week. The chi squared criterion was used to identify the distribution function parameters, and was also used to compare the fit of lognormal and Weibull functions to a voltage dip distribution. Furthermore, a hill climbing algorithm used for minimizing the chi squared criterion, and the best probability distributions used for fitting the measured data were presented and analyzed in the paper.

Although there were more events with industrial consumers than domestic, the most number of measured voltage dips for both consumer groups were in two depth categories: $10-15 \% U_{n}$ and $15-30 \% U_{n}$. So, these two depth categories were analyzed and described by means probability functions.

10-15\% $U_{n}$ voltage dip distribution were described pretty well by both lognormal and Weibull probability distributions, in both cases - domestic and industrial consumers. However, in both cases lognormal probability 
distribution had lower chi square error. So, lognormal probability distribution is most suitable for describing 10-15\% $U_{n}$ voltage dip distribution for both groups of consumers.

In the case of $15-30 \% U_{n}$ voltage dip distribution, domestic consumers, both probability functions don't fit it as well as in the previous depth category. Although lognormal and Weibull functions have similar shapes, lognormal probability distribution has lower chi square error. In the same depth category, for industrial consumers, Weibull probability distribution has higher chi square error, and also does not fit basic shape of measured dip distribution.

So, according to above calculations and analyses, for both groups of consumers, domestic and industrial, lognormal probability distribution is most suitable for describing measured voltage sag distributions.

RMS variation indices confirm results obtained by probability distribution functions, and provide easier comparison of voltage sags characteristics for two analized groups of substations.

\section{REFERENCES}

[1] FERRACCI, P.: Power Quality, Cahier Technique Schneider Electric no. 199, Oct 2001.

[2] Power Quality in European Electricity Supply Networks $-1^{\text {st }}$ edition, Eurelectric, Belgium, Feb 2002.

[3] BOLLEN, M. H. J.: Understanding Power Quality Problems: Voltage Sags and Interruptions, IEEE Press, New York, 1999.

[4] DJOKIĆ, S. Ž.-MiLANOVIĆ, J. V.-CHAPMAN, D. J.McGRANAGHAN, M. F.: Shortfalls of Existing Methods for Classification and Presentation of Voltage Reduction Events, IEEE Transactions on Power Delivery 20 No. 2 (April 2005).

[5] BOLleN, M. H. J.-YU-HUAGU, I.: Signal Processing of Power Quality Disturbances, IEEE Press, Piscataway, NJ, 2006.

[6] BROOKS, D. L.-DUGAN, R. C.-WACLAWIAK, M.-SUNDARAM, A.: Indices for Assessing Utility Distribution System RMS Variation Performance, IEEE Trans. on Power Delivery 13 No. 1 (Jan 1998), 254-259.

[7] BROWN, R. E. : Electric Power Distribution Reliability, Marcel Dekker, Inc., New York, 2002.

[8] PARK, C-H.-JANGG. : Stochastic Estimation of Voltage Sags in a Large Meshed Network, Transactions on Power Delivery 22 No. 3 (July 2007).
[9] ŠLJIVAC, D.-KLAIĆ, Z.- ŠIMIĆ, Z.: Indicators of quality and reliability of electrical power supply (Pokazatelji kvalitete i pouzdanosti napajanja električnom energijom, Elektroenergetika - časopis za proizvodnju, prijenos, distribuciju i korištenje električne energije 5 (2008), 31-38. (in Croatian)

10] KLAIC, Z.-NIKOLOVSKI, S.-BAUS, Z.: Statistical Analysis of Voltage Sags in Distribution Network According to EN 50160 Standard - Case Study, $19^{\text {th }}$ International Conference and Exhibition on Electricity Distribution (CIRED), Vienna, 2007.

Received 10 March 2011

Zvonimir KLAIĆ received his BSc degree in 2000 in the field of Power System Engineering, MSc degree in 2006 and PhD degree in 2011 from the Faculty of Electrical Engineering Osijek, University of Josip Juraj Strossmayer Osijek. Currently he is working on the Power System Engineering Department at the Faculty of Electrical Engineering, University of Osijek, Croatia. His main interest is in the quality of electric power supply. He participated in publishing several scientific papers and projects. He is a member of Croatian National Committee of CIGRE and CIRED.

Damir ŠLJIVAC obtained his BSc degree in 1997 from the Faculty of Electrical Engineering, Osijek, MSc degree in 2000 and $\mathrm{PhD}$ degree in 2005 from the Faculty of Electrical Engineering and Computing Zagreb, Croatia in the field of the Power System Engineering. Currently he is an Associate Professor at the Power System Engineering Department and vice-dean at Faculty of Electrical Engineering Osijek, Croatia. His main interest is in power system reliability, economics and renewable energy sources. He has published over 50 papers in those fields. He is a member of IEEE Power Engineering Society, IEEE Reliability Society, IEEE Croatia Section, Executive Board of National Council for Energy Of Croatian Academy for Science and Art and Croatian National Committee of CIGRE and CIRED.

Zoran BAUS, PhD, was born on June 15, 1951. He obtained his BSc degree (1975), MSc degree (1987), in electrical engineering and his $\mathrm{PhD}$ degree from the Faculty of Electrical and Computing Engineering, Zagreb, Croatia in 2004. His major fields of interest include Intelligent Control (fuzzy control and optimization) and Power System Analyses. Presently, he is an Assistant Professor at the Power System Engineering Department at Faculty of Electrical Engineering Osijek, Croatia. 